Revista Brasil. Bot., V.31, n.4, p.679-687, out.-dez. 2008

\title{
Fenologia reprodutiva de quatro espécies de Sapotaceae na restinga de Maricá, $\mathbf{R J}^{\mathbf{1}}$
}

\author{
REJANE GOMES ${ }^{2,3}$, MARIA CÉLIA BEZERRA PINHEIRO² e HELOÍSA ALVES DE LIMA²
}

(recebido: 03 de maio de 2007; aceito: 25 de setembro de 2008)

\begin{abstract}
Reproductive phenology of four species of Sapotaceae at the Maricá, RJ sand bar). The purpose of this work was to record the occurrence of phenological events related to the flowering and fructification of Pouteria venosa (Mart.) Baheni, P. psammophila (Mart.) Radlk., Manilkara subsericea (Mart.) Dubar e Sideroxylon obtusifolium (Roem. \& Schult.) T. D. Penn. at the Maricá-RJ sand bar in the years of 2003 to 2005. Pouteria venosa produced flowers from May to October, whereas M. subsericea flowered from May to September, and S. obtusifolium produced flowers from August to November. During the period of studies P. psammophila did not flower. The fruits are berry-type, and display synchronism in the maturing and release of their seeds in the months of February and March. Flowering and fructification for the three species is annual, with a negative and significant correlation only between flowering and temperature. For S. obtusifolium correlation was positively significant between fruit development and the abiotic factors of temperature and precipitation.
\end{abstract}

Key words - Manilkara subsericea, phenology, Pouteria venosa, Sapotaceae, Sideroxylon obtusifolium

RESUMO - (Fenologia reprodutiva de quatro espécies de Sapotaceae na restinga de Maricá, RJ). O objetivo desse trabalho foi registrar a ocorrência dos eventos fenológicos relacionados com a floração e a frutificação de Pouteria venosa (Mart.) Baheni, P. psammophila (Mart.) Radlk., Manilkara subsericea (Mart.) Dubar e Sideroxylon obtusifolium (Roem. \& Schult.) T. D. Penn. na restinga de Maricá-RJ nos anos de 2003 a 2005. P. venosa produziu flores de maio a outubro, enquanto $M$. subsericea floresceu de maio a setembro e $S$. obtusifolium produziu flores de agosto a novembro. Pouteria psammophila não floresceu no período de estudo. Os frutos são do tipo baga e apresentam sincronia na maturação e liberação de suas sementes, nos meses de fevereiro e março. A floração e a frutificação para as três espécies é anual, com correlação significativa negativa apenas entre a floração e a temperatura. Para S. obtusifolium a correlação foi significativa positiva entre o desenvolvimento dos frutos e os fatores abióticos temperatura e precipitação.

Palavras-chave - fenologia, Manilkara subsericea, Pouteria venosa, Sapotaceae, Sideroxylon obtusifolium

\section{Introdução}

A fenologia pode ser definida como o estudo dos eventos do ciclo de vida, das causas de sua ocorrência com relação às forças seletivas bióticas e abióticas, bem como da inter-relação entre as fases caracterizadas por esses eventos, em uma ou diferentes espécies (Lieth 1974). O conhecimento da fenologia é baseado nas observações de estádios de desenvolvimento extremamente visíveis (fenofases), como por exemplo, a germinação das sementes, a emergência das gemas, o desenvolvimento das folhas, a floração, a frutificação, a descoloração das folhas e a senescência. A organização das datas fenológicas proporciona informações ecológicas importantes sobre a duração média das diferentes fenofases das distintas

1. Parte da tese de doutorado da primeira autora, Programa de PósGraduação em Ciências Biológicas - Botânica da Universidade Federal do Rio de Janeiro.

2. Universidade Federal do Rio de Janeiro, Museu Nacional, Departamento de Botânica, Laboratório de Biologia Reprodutiva. Quinta da Boa Vista s/nº , São Cristóvão, 20940-040. Rio de Janeiro, RJ, Brasil.

3. Autor para correspondência: rejanegome@gmail.com espécies em uma área, e sobre o local e as diferenças determinadas pelo clima nas datas de início dessas fases (Larcher 2000). A fenologia é reconhecida, já há algum tempo, como uma das mais importantes linhas da pesquisa ecológica, sendo considerada como um dos melhores parâmetros a ser utilizado para caracterizar ecossistemas (Lieth 1974). Os dados fenológicos, quando obtidos de forma sistemática, reúnem importantes informações sobre o estabelecimento de espécies e períodos de crescimento e reprodução, de modo a caracterizar e definir a disponibilidade dos recursos para os agentes polinizadores e dispersores (Frankie et al. 1974).

Os estudos fenólogicos para a família Sapotaceae mostram uma variedade de padrões: floração e frutificação anual com um único episódio ao ano, para Manilkara amazonica (Huber) Chevalier, na Reserva Biológica de Campina, em Manaus (Alencar 1990), Chrysophyllum gonocarpum (Miq.) Engl., em Londrina e no Paraguai e Cynodendron marginatum (Hook. \& Arn.) Baehni, no Paraguai (Ortega 1986, Justiciano \& Fredericksen 2000, Bianchi et al. 2006); vários episódios ao longo do ano para as espécies Glycoxylon inophyllum (Mart.) 
Ducke, na Reserva Biológica de Campina, em Manaus (Alencar 1990), Argania spinosa (L.) Skeels, em Israel (Nouaim et al. 1991), Pouteria caimito (Ruiz \& Pav.) Radlk., na Amazônia Central (Falcão \& Clement 1999) e Sideroxylon capiri (A. DC.) Pittier, na Costa Rica (Garcia \& Stefano 2003).

Estudos fenológicos para a vegetação de restinga são escassos e os únicos trabalhos existentes são os de Talora \& Morellato (2000), no Parque Estadual da Serra do Mar, núcleo Picinguaba, Ubatuba, SP e de Marques \& Oliveira (2004), em dois tipos de florestas de restinga (inundável e não inundável), na Ilha do Mel, Paranaguá, PR.

O objetivo desse trabalho foi registrar a época em que ocorrem os eventos fenológicos relacionados com a floração e frutificação de quatro espécies da família Sapotaceae na restinga de Maricá-RJ: Pouteria venosa (Mart.) Baehni, P. psammophila (Mart.) Radlk., Manilkara subsericea (Mart.) Dubar e Sideroxylon obtusifolium (Roem. \& Schult.) T. D. Penn. subsp. obtusifolium. As três últimas encontram-se citadas como ameaçadas de extinção nas categorias rara ou vulnerável (Mello-Filho et al. 1992, Andrade \& Andrade 1993, IUCN 1994 apud Ferreira 2000, Ferreira et al. 1989 apud Ferreira 2000). $\mathrm{Na}$ área de estudo ocorre ainda P. caimito (Ruiz \& Pav.) Radlk., não incluída no trabalho pelo pequeno número de indivíduos (quatro). As principais questões levantadas foram: 1. As espécies apresentam comportamento fenológico sazonal? 2. Em qual época do ano as fenofases ocorrem? 3. Há sincronia da floração e da frutificação entre as espécies? 4 . Os fatores climáticos influenciam na floração e na frutificação?

\section{Material e métodos}

Área de estudo - O estudo da fenologia de Pouteria venosa, Manilkara subsericea e Sideroxylon obtusifolium subsp. obtusifolium foi desenvolvido em vegetação de restinga, na Área de Proteção Ambiental (APA) de Maricá, Estado do Rio de Janeiro, entre as coordenadas de $22^{\circ} 56^{\prime} 15^{\prime \prime}$ a $22^{\circ} 58^{\prime} 12^{\prime \prime} \mathrm{S}$ e 42 $54^{\prime} 08^{\prime \prime}$ a 42 $54^{\prime} 30^{\prime \prime}$ W (Louro \& Santiago 1984).

Estudos relacionados com a caracterização macroclimática de Maricá, ao longo do período de 1989 a 2000, mostram que a temperatura mínima do ar é menor no inverno $\left(8,6^{\circ} \mathrm{C}\right.$ a $15,2^{\circ} \mathrm{C}$ ), sendo julho o mês mais frio, e maior no verão (sempre acima de $15^{\circ} \mathrm{C}$ ), sendo fevereiro o mês mais quente; a temperatura máxima do ar no inverno está entre $29,2^{\circ} \mathrm{C}$ e $37,3^{\circ} \mathrm{C}$, enquanto no verão é sempre maior que $33^{\circ} \mathrm{C}$, chegando a $37,7^{\circ} \mathrm{C}$; a precipitação pluviométrica média anual é de $1130 \mathrm{~mm}$, concentrada no verão e reduzida no inverno, não havendo meses com déficit hídrico (Mantovani \& Iglesias 2001).
Os dados climatológicos do presente trabalho foram obtidos através do Instituto Nacional de Metereologia (INMET - 6o Distrito-RJ, estação 83089) para a região de Maricá, no período de janeiro de 2003 a março de 2005. Os dados referentes aos meses de abril de 2005 a dezembro de 2005 foram obtidos através da estação climatológica/ agroclimatológica do INMET no trecho Niterói, Barra de Maricá. Foram consideradas duas estações durante o ano, conforme outros trabalhos para a área (Correia et al. 2005, 2006): uma de outubro a março, com chuvas freqüentes e maiores temperaturas, e outra de abril a setembro, menos úmida e com temperaturas mais amenas. Durante o período de observações, a precipitação variou de 34,4 a $258,7 \mathrm{~mm}$ na estação mais úmida, e de 5,7 a $246 \mathrm{~mm}$ na estação menos úmida, tendo-se registrado períodos de déficit hídrico nos três anos de estudo. $\mathrm{O}$ mês de maior estiagem foi agosto e o período de maior precipitação ocorreu entre os meses de fevereiro e março. A temperatura média anual foi de $23,6^{\circ} \mathrm{C}$, sendo menor durante os meses de julho e agosto $\left(19,9\right.$ a $\left.20,1^{\circ} \mathrm{C}\right)$ e maior durante o mês de fevereiro, chegando a $28,1^{\circ} \mathrm{C}$. Os meses foram denominados secos quando a precipitação pluviométrica média foi menor ou igual ao dobro da temperatura média (Henriques et al. 1986).

$\mathrm{Na}$ área de estudo há uma vegetação de restinga, com cobertura vegetal relativamente preservada nos cordões interno e externo, onde ocorrem as espécies estudadas. No cordão externo a vegetação é predominantemente arbustiva, com áreas de moitas intercaladas por espaços desnudos, e no cordão interno é arbórea, com altura média de 4 a 8 m (Silva \& Oliveira 1989). Sideroxylon obtusifolium subsp. obtusifolium é um arbusto, com cerca de $1,5 \mathrm{~m}$, que ocorre sobre o cordão externo; Pouteria venosa, P. psammophila e M. subsericea estão presentes no cordão interno e apresentam hábito arbóreo, com cerca de $2 \mathrm{~m}$. Esta última espécie também é encontrada no cordão externo, onde exibe hábito arbustivo, com cerca de $0,5 \mathrm{~m}$.

Observações fenológicas - Foram realizadas excursões mensais, de janeiro/2003 a dezembro/2005, e quinzenais, ao longo da floração (emissão de botões e de flores) e da frutificação das espécies (desenvolvimento de frutos e dispersão dos mesmos). As observações foram realizadas em 12 indivíduos adultos de cada espécie, amostra considerada satisfatória por Fournier \& Charpantier (1975), marcadas ao acaso, anotando-se o início e o término de cada evento, bem como as características observadas ao longo das fenofases.

Os padrões de floração foram descritos segundo Newstrom et al. (1994), considerando-se a freqüência, a sincronia, a regularidade e a duração de cada fenofase.

Para a análise dos dados, uma vez que as variáveis bióticas não apresentaram distribuição normal (teste de Kolmogorov-Smirnov para normalidade), foi realizado o teste de correlação de Spearman $\left(r_{s}\right)$, entre o número de indivíduos de uma espécie, bem como das espécies da família, em cada fenofase, e as variáveis climáticas (temperatura média e precipitação), com registros de 36 meses. Para tal foi utilizado o Programa Statistica 6.0 (Statsoft 1991). 
As observações morfológicas referentes ao crescimento, tamanho e coloração dos frutos e sementes oriundas de polinização natural, foram realizadas no campo e no laboratório com o auxílio do microscópio estereoscópico e de um paquímetro. Os frutos foram acompanhados desde o início do desenvolvimento até a maturação, sendo coletados quinzenalmente 10 frutos de cada espécie para medições. Para o cálculo do percentual de aborto dos frutos foram marcados 28 frutos jovens de $P$. venosa, 210 de $M$. subsericea e 87 de S. obtusifolium, os quais foram acompanhados quinzenalmente até a maturação, visando registrar a queda ao longo do desenvolvimento dos mesmos.

\section{Resultados}

Floração - Na restinga de Maricá, Pouteria venosa, Manilkara subsericea e Sideroxylon obtusifolium apresentaram floração sazonal (na estação menos úmida e mais fria do ano), anual e regular. Pouteria psammophila não emitiu botões nem flores durante todo o período de estudo. Os registros tomados ao longo de 36 meses estão resumidos na figura 1. As espécies de Sapotaceae apresentaram períodos de floração superpostos, sendo que $P$. venosa e $M$. subsericea iniciaram a emissão de botões e de flores praticamente juntas e apresentaram sincronia nos períodos de pico de floração. S. obtusifolium floresceu sequiencialmente, embora grande parte do período de floração tenha sido concomitante com as outras duas espécies. No ano de 2005 houve uma sobreposição dos períodos de floração das três espécies em estudo, em função de um atraso no início da floração de $P$. venosa e de $M$. subsericea e um adiantamento na floração de $S$. obtusifolium.

Pouteria venosa apresentou floração longa, cada indivíduo florindo durante aproximadamente 150 dias. Considerando-se plantas individuais, observou-se a emissão de todos os primórdios florais correspondentes a um episódio de floração cerca de dois meses antes do início da floração. Entretanto, o acompanhamento destes primórdios mostrou que houve um desenvolvimento diferenciado dos botões, de forma que aproximadamente $20 \%$ atingiram a maturidade no primeiro e no segundo mês de floração, enquanto $60 \%$ demoraram de dois a três meses e os demais (20\%) permaneceram em estado de latência, voltando a se desenvolver após cinco a sete meses da emissão.

No ano de 2003, dez indivíduos de $P$. venosa floresceram de maio a outubro (seis meses), com pico nos meses de junho a setembro, período no qual $83 \%$ das plantas estavam em plena floração (figura 2). Neste ano, não houve déficit hídrico durante a floração, ao

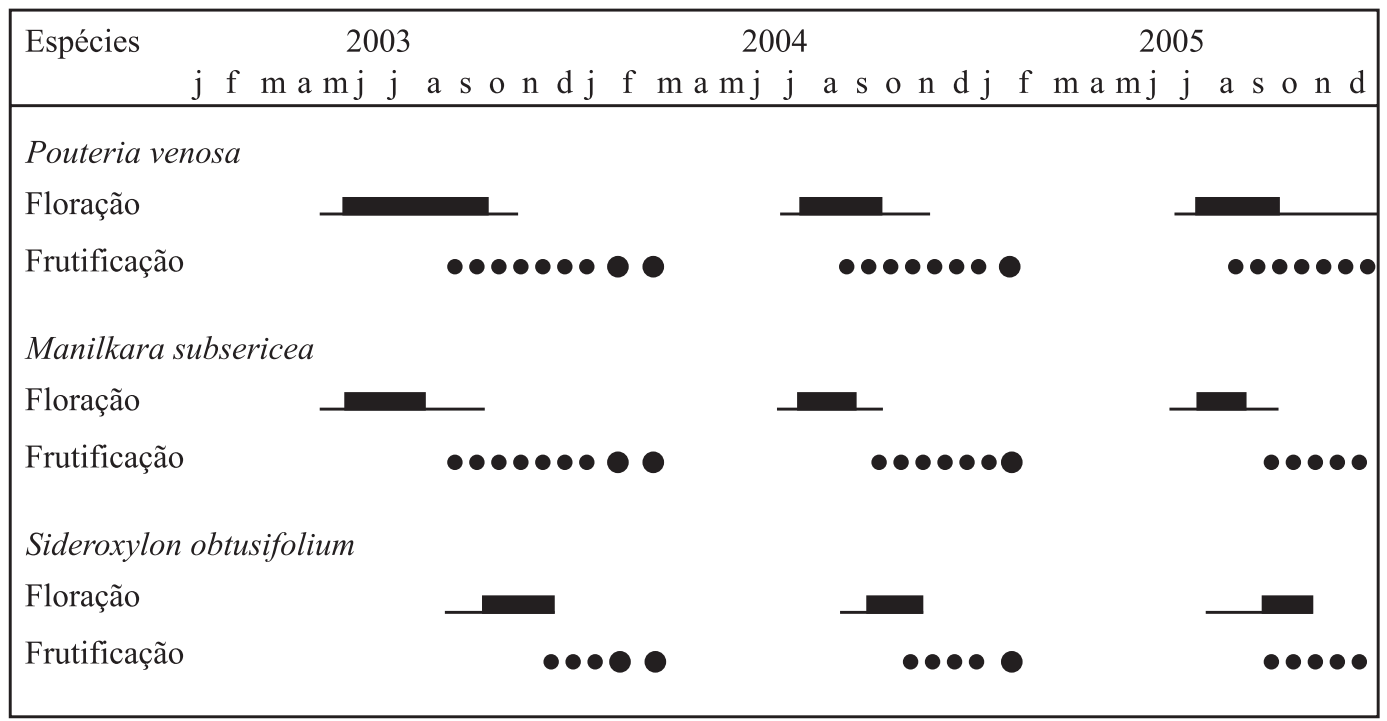

Figura 1. Ocorrência dos eventos fenológicos para as espécies Pouteria venosa, Manilkara subsericea e Sideroxylon obtusifolium subsp. obtusifolium observadas na restinga de Maricá-RJ (2003-2005).(_ = produção de flores; - = pico de floração; $\bullet \bullet=$ desenvolvimento dos frutos; $\bullet \bullet=$ dispersão de frutos e sementes).

Figure 1. Occurrence of the phenological events of Pouteria venosa, Manilkara subsericea and Sideroxylon obtusifolium observed in restinga of Maricá-RJ (2003-2005). (_ = production of flowers; $\boldsymbol{z}=$ = peak of the flowering; $\bullet \bullet \bullet=$ development of fruits; $\bullet \bullet=$ fruits and seeds set). 
passo que nos dois anos seguintes o pico de floração coincidiu com uma queda acentuada da precipitação, cujos índices alcançaram 15,1 mm (2004) e 5,7 mm (2005), caracterizando períodos secos. No ano de 2004, a floração de $P$. venosa ocorreu nos meses de julho a outubro (quatro meses), e em 2005, de julho a dezembro (seis meses), e todas as plantas marcadas floresceram. Nestes dois anos as plantas exibiram períodos de floração menos extensos e conspícuos do que em 2003, e o pico de floração restringiu-se aos meses de agosto e setembro (figura 2).

Em M. subsericea a duração da floração foi intermediária em nível de população e breve em nível individual, cada planta estendendo o evento por cerca de 30 dias, com forte sincronia intra-específica e produção conspícua de flores, caracterizando uma floração em massa. Os primórdios florais foram emitidos cerca de um mês antes do início da fenofase de floração. O amadurecimento desses primórdios foi sincrônico, diferenciando-se, neste aspecto, do amadurecimento paulatino dos botões, verificado em $P$. venosa. Em 2003, a população de $M$. subserice a floresceu de maio a setembro, enquanto que em 2004 e 2005 o período de floração foi mais curto, de julho a setembro (figura 2). Os picos de floração ocorreram nos meses de junho e julho (2003) e em agosto (2004 e 2005) e coincidiram com os meses
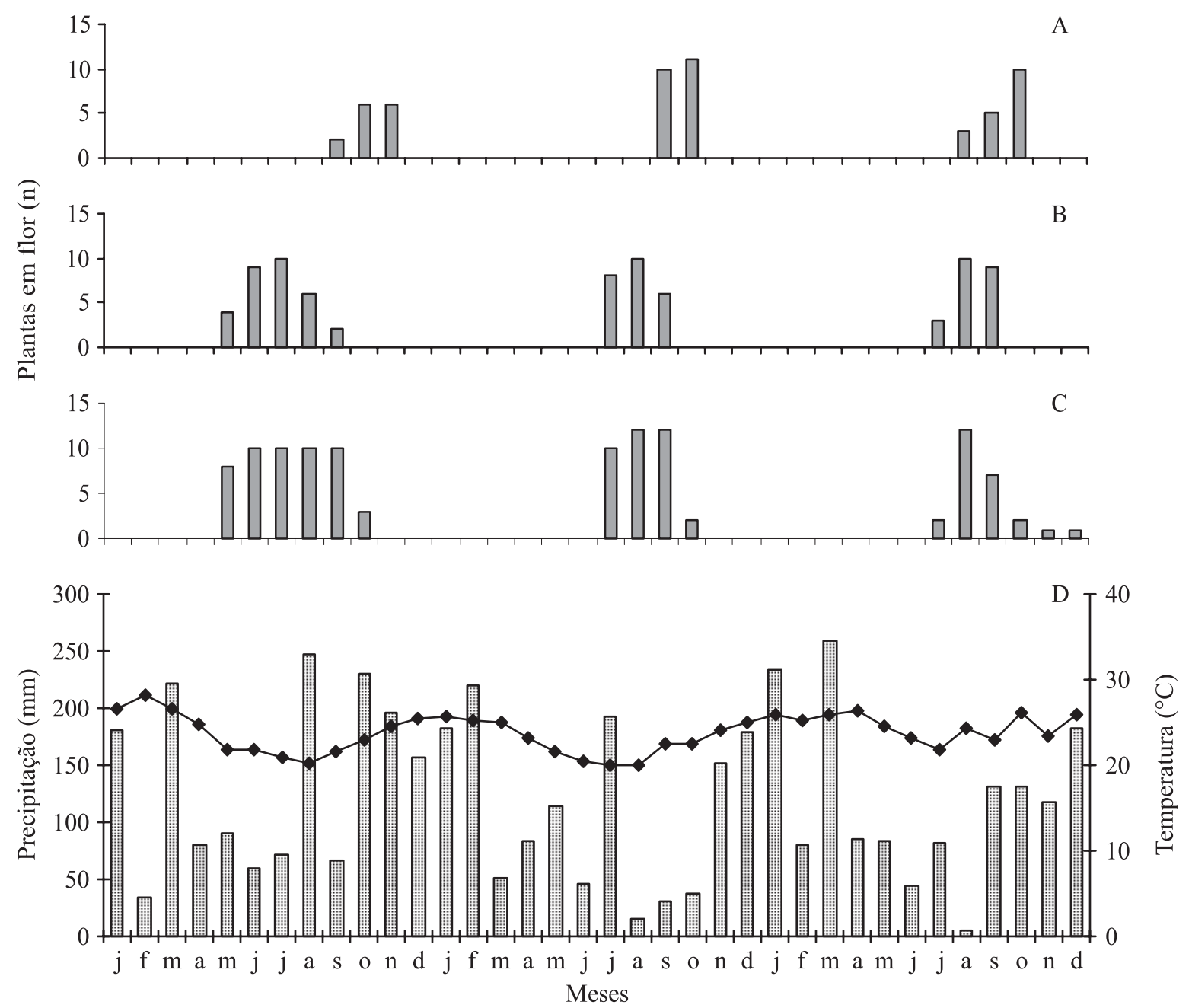

Figura 2. Distribuição mensal do número de plantas com flores entre 2003 e 2005. A. Sideroxylon obtusifolium (Roem. \& Schult.) T. D.Penn. B. Manilkara subsericea (Mart.) Dubar. C. Pouteria venosa (Mart.) Baehni. D. Gráfico de precipitação e temperatura, entre 2003 e 2005, para Maricá, Rio de Janeiro, Brasil $(\bullet=$ Precipitação, $\square=$ Temperatura $)$.

Figure 2. Mensal distribution of the number of flowering plants between 2003 and 2005. A. Sideroxylon obtusifolium (Roem. \& Schult.) T. D. Penn. B. Manilkara subsericea (Mart.) Dubar. C. Pouteria venosa (Mart.) Baehni. D. Graphic of rainfall and temperature, between 2003 and 2005, for Maricá, Rio de Janeiro State, Brazil $(\bullet=$ Rainfall, 回 Temperature). 
que apresentaram os menores índices pluviométricos ao longo da floração, chegando a ser considerados secos nos dois últimos anos.

Nos três anos de estudo, ramos de todas as plantas de $M$. subsericea marcadas exibiram galhas de dípteros Cecidomyiidae, que danificaram a emissão dos primórdios florais e foliares (março a maio), os quais chegaram a desenvolver folhas e flores mal formadas. Somente nos meses de maio e junho, uma nova emissão de primórdios originou folhas e flores normais.

A floração de $S$. obtusifolium teve duração intermediária, ocorrendo nos meses de agosto a novembro, sendo o tempo de floração de cada indivíduo de aproximadamente 60 dias, com pico no mês de outubro (figura 2), coincidindo com a transição do período menos úmido para o chuvoso. Os primórdios florais foram emitidos cerca de um mês antes do início da floração, e apresentaram desenvolvimento rápido e sincrônico. No período de estudo, a floração ocorreu nos meses de setembro a novembro (2003), setembro a outubro (2004) e agosto a outubro (2005).

Frutificação - A frutificação para as três espécies foi anual e regular, ocorrendo durante a estação com maior pluviosidade e temperaturas mais elevadas. Manilkara subsericea, $P$. venosa e $S$. obtusifolium exibiram maturação e liberação das sementes nos meses de fevereiro e março. Ressalta-se, entretanto, um alto índice de aborto de frutos, principalmente, antes da seguinte fase de crescimento acelerado dos mesmos: P. venosa $(96,4 \%)$, M. subsericea (90\%) e S. obtusifolium $(70,1 \%)$. As três espécies apresentam frutos carnosos e latescentes.

As curvas de crescimento dos frutos e das sementes de $P$. venosa, $M$. subsericea e $S$. obtusifolium, desde a polinização até a liberação das sementes, podem ser vistas na figura 3. As três espécies apresentaram uma curva dupla sigmoidal para o crescimento dos frutos, com as seguintes fases subseqüentes: (I) um período inicial de crescimento lento, (II) uma primeira fase de crescimento rápido, (III) um segundo período de crescimento lento e (IV) um segundo período de crescimento rápido.

Em $P$. venosa, os frutos levaram aproximadamente 140 dias (20 semanas) para a maturação (figura 3), a qual foi marcada pela mudança de cor do pericarpo de verde para laranja. A frutificação ocorreu de setembro a março no ano de 2003, e de setembro a fevereiro nos anos de 2004 e 2005, sendo fevereiro/março os meses com frutos maduros.

Em M. subsericea, os frutos levaram cerca de 110 dias (16 semanas) para a maturação (figura 3), quando o pericarpo muda da cor verde para vermelho vinho. A

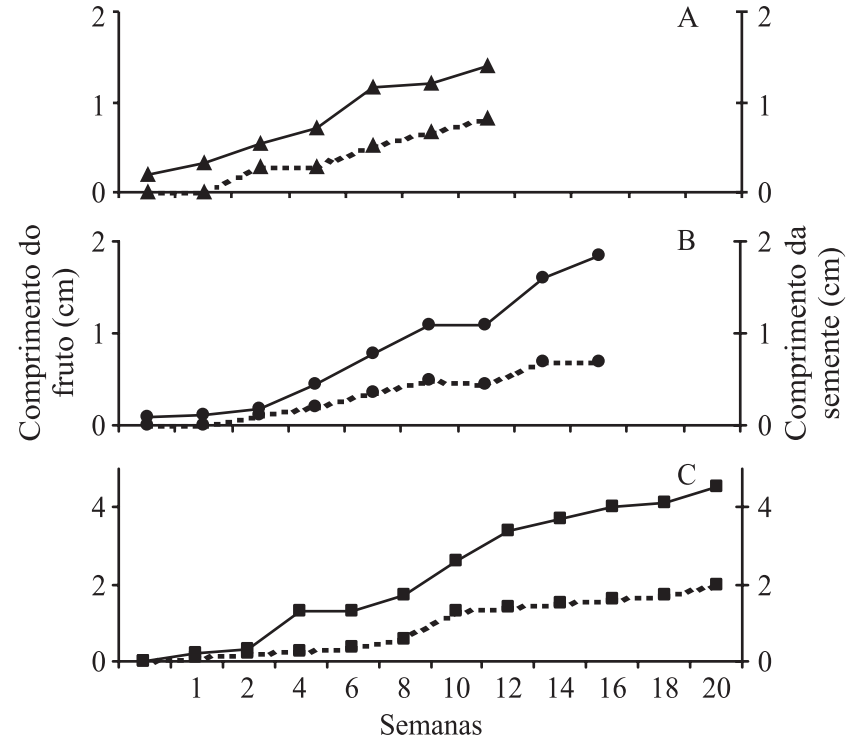

Figura 3. Curva de crescimento dos frutos ( - ) e das sementes ( •••) das espécies estudadas, resultantes de polinização natural. A. Sideroxylon obtusifolium. B. Manilkara subsericea. C. Pouteria venosa.

Figure 3. Growth curve of fruits ( - ) and seeds ( $\bullet \bullet \bullet$ ) of the studied species, resultant of natural pollination. A. Sideroxylon obtusifolium. B. Manilkara subsericea. C. Pouteria venosa.

frutificação ocorreu nos meses de setembro a março (2003), de novembro a fevereiro (2004) e de setembro a fevereiro (2005), sendo fevereiro/março os meses com frutos maduros.

Em S. obtusifolium, os frutos levaram cerca de 80 dias (12 semanas) para alcançar a maturidade (figura 3), tendo sua coloração alterada de verde para preto. No ano de 2003, a frutificação ocorreu de dezembro a março, enquanto em 2004, de novembro a fevereiro e, em 2005, de outubro a fevereiro, sendo fevereiro/março os meses com frutos maduros.

Correlação com fatores abióticos - O índice de correlação de Spearmam apontou para a família Sapotaceae, na restinga, uma correlação significativamente negativa entre a floração e os fatores abióticos temperatura média e precipitação e uma correlação significativamente positiva entre a liberação de sementes e a temperatura média. Entretanto, analisando-se as três espécies separadamente esse índice mostrou correlação negativa significativa apenas entre a floração e a temperatura média, para todas elas. Para S. obtusifolium também houve correlação significativa positiva entre o desenvolvimento dos frutos e os fatores abióticos temperatura média e precipitação (tabela 1). 
Tabela 1. Índices de correlação de Spearman $\left(\mathrm{r}_{\mathrm{s}}\right)$ obtidos na análise de correlação entre os fatores climáticos (temperatura média e precipitação) e as fenofases de floração, desenvolvimento de frutos e dispersão de sementes das espécies de Sapotaceae da restinga de Maricá, RJ. Entre parênteses o valor do índice de correlação de Spearman $\left(\mathrm{r}_{\mathrm{s}}\right)$ para $P<0,05$. (Tmed $=$ temperatura média; PPT = precipitação; * = significativo).

Table 1. Spearman correlation $\left(r_{s}\right)$ tests between each climatic factors (temperature and rainfall) and the flowering, fruit development and seed dispersion phenophases of species of Sapotaceae in restinga of Maricá, RJ. Correlation index $\left(\mathrm{r}_{\mathrm{s}}\right)$ between brackets for $P<0,05$. (Tmed $=$ mean temperature; $\mathrm{PPT}=$ rainfall; $*=$ significative).

\begin{tabular}{llll}
\hline \multirow{2}{*}{ Flores } & $\begin{array}{c}\text { Desenvolvimento } \\
\text { dos frutos }\end{array}$ & $\begin{array}{c}\text { Liberação } \\
\text { das sementes }\end{array}$ \\
\hline Sapotaceae & Tmed $(-0,75)^{*}$ & Tmed $(0,32)$ & Tmed $(0,51)^{*}$ \\
& PPT $(-0,35)^{*}$ & PPT $(0,26)$ & PPT $(0,09)$ \\
Pouteria venosa & Tmed $(-0,63)^{*}$ & Tmed $(0,12)$ & Tmed $(0,26)$ \\
& PPT $(-0,28)$ & PPT $(0,16)$ & PPT $(0,09)$ \\
Sanilkara subsericea & Tmed $(-0,65)^{*}$ & Tmed $(0,19)$ & Tmed $(0,18)$ \\
& PPT $(-0,32)$ & PPT $(-0,02)$ & PPT $(-0,02)$ \\
& Tmed $(-0,55)^{*}$ & Tmed $(0,44)^{*}$ & Tmed $(0,32)$ \\
& PPT $(-0,11)$ & PPT $(0,39)^{*}$ & PPT $(0,19)$ \\
\hline
\end{tabular}

\section{Discussão}

A correlação negativa altamente significativa entre a floração das três espécies (isoladamente e em conjunto) e a temperatura sugere que este fator abiótico seja importante para o início do período reprodutivo das Sapotaceae na restinga. Embora na restinga de Barra de Maricá a precipitação pluviométrica média mensal durante o inverno apresente queda significativa em comparação com o verão, ocorrem meses de alta pluviosidade no inverno e de baixa pluviosidade no verão (Mantovani \& Iglesias 2001). Além disso, a ocorrência de orvalho e de lençóis freáticos pouco profundos (Dau 1960), importantes fontes de água para as plantas, podem favorecer uma relação mais forte entre a floração e a temperatura média do que entre a floração e a precipitação pluviométrica. Entretanto, quando as três espécies são analisadas conjuntamente, a fenofase de floração também se mostrou correlacionada negativa e significativamente com a pluviosidade.

O estudo fenológico de cinco espécies arbóreas tropicais de Sapotaceae na Reserva Ducke, Manaus, também registrou floração durante a estação seca (emissão de botões e floração), com pequena variação temporal entre as espécies (Alencar 1994). Na floresta da Guiana, 17 espécies de Sapotaceae floresceram principalmente na estação mais ensolarada, correspondendo aos meses com menor pluviosidade (Steege \& Persaud 1991). Outros estudos fenológicos assinalam floração na estação seca para espécies de Sapotaceae, entre elas: Sideroxylon capiri em floresta seca tropical da Costa Rica (Garcia \& Di Stefano 2003), Bumelia sartorum Mart., no vale do rio Paraguaçu, Bahia (Carvalho \& Marchini 1999), Chrysophyllum gonocarpum, em floresta semi-decídua, Londrina, sul do Brasil (Bianchi et al. 2006) e $C$. panamense Pittier, em Barro Colorado, Panamá (Croat 1969). O predomínio de espécies de Sapotaceae florescendo ao longo de períodos com menores índices de precipitação, não só na restinga, sugere a presença de limitações filogenéticas relacionadas com a época da floração.

Ressalta-se que, na restinga de Maricá, a floração das Sapotaceae ao longo da estação mais fria e menos úmida do ano não é um padrão usual, uma vez que, de um modo geral, nas formações vegetacionais atlânticas observa-se um maior número de espécies em florescimento a partir de novembro, no período mais quente e mais úmido do ano e com aumento no fotoperíodo, decaindo em junho, já no período mais frio e menos úmido (Talora \& Morellato 2000, Marques \& Oliveira 2004).

Os padrões de floração e de frutificação das espécies em estudo mostraram-se sazonais, anuais e regulares. Na Reserva Ducke, entretanto, os padrões de floração de Sapotaceae foram variados, com espécies apresentando padrão anual regular (evento em todos os anos), anual irregular (evento nem sempre presente em todos os anos), anual alternado (evento anual em anos seguidos, mas com alternância de dois a três anos) e bianual (Alencar 1994). 
A ausência de fenofases reprodutivas em $P$. psammophila ao longo do período de estudo sugere que nesta espécie o padrão de floração possa se enquadrar nos tipos alternados ou irregulares descritos por Alencar (1994) para algumas espécies de Sapotaceae da Reserva Ducke. Somente estudos de longa duração poderão definir os padrões dessas espécies com segurança.

Muito embora as florações de $M$. subsericea e de $P$. venosa ocorram no mesmo período, ou seja, que as espécies apresentem sincronia na floração, a primeira apresenta flores com antese diurna, alvas e de odor agradável, enquanto que $P$. venosa apresenta flores com antese noturna, de cor verde e com odor desagradável, não compartilhando os mesmos polinizadores. Já $M$. subsericea e $S$. obtusifolium, que apresentam flores com características morfológicas e biológicas muito parecidas e atraem os mesmos polinizadores, exibem florações sequienciais, com períodos de superposição, mas com picos separados (Rejane Gomes, dados não publicados).

Diferenças na fenologia da floração entre espécies da mesma família que ocorrem na mesma área e compartilham polinizadores foram registradas nas famílias Bignoniaceae (Gentry 1974), Malpighiaceae (Barros 1992) e Rubiaceae (Almeida \& Alves 2000). A competição interespecífica por polinizadores e a conseqüente transferência de pólen interespecífico, em tese, podem favorecer a divergência dos períodos de floração, já que tais fenômenos acarretam redução das taxas de polinização e, portanto, de produção de sementes, além de, no último caso, ocorrer produção de híbridos menos ou não adaptados. Segundo Bawa (1983), um teste crítico para verificar a hipótese da divergência dos períodos de floração, em espécies que compartilham os mesmos polinizadores, requeriria a demonstração de que a segregação temporal dos períodos de floração entre espécies competidoras não se dá ao acaso, e que a superposição dos eventos florais resulta em redução na produção de sementes decorrente de fluxo gênico interespecífico, o que experimentalmente nem sempre é possível.

Dípteros Cecidomyiidae também foram observados como galhadores das folhas de $P$. venosa e de $P$. caimito (Maia 2001) e como polinizadores de $P$. venosa na restinga de Maricá (Rejane Gomes, dados não publicados).

Muito embora as três espécies tenham períodos de desenvolvimento e de liberação de frutos incluídos na estação do ano mais chuvosa e com temperaturas mais elevadas, somente em S. obtusifolium a frutificação apresentou correlação significativa da temperatura média e da precipitação na época de produção de frutos.
Considerando-se apenas o período de liberação das sementes, a família como um todo apresentou correlação positiva significativa com a temperatura média, mas não com a precipitação. De um modo geral, o período de frutificação para as espécies da família Sapotaceae ocorre na estação mais chuvosa, podendo-se citar: Pouteria guianensis Aubl., Radlkoferella macrocarpa (Huber) Aubrév., Chrysophyllum oppositum (Ducke) Ducke, Ragala ucuquirana-branca (Aubrév. \& Pellegr.) W. Rodr.e Ragala ulei (K. Krause) Aubrév. na Amazônia (Alencar 1994), Chrysophyllum gonocarpum em Floresta Semidecídua em Londrina (Bianchi et al. 2006) e Glycoxylon inophyllum na Reserva Biológica de Campina em Manaus (Alencar 1990). A frutificação na estação de transição chuvosa-seca é registrada para Manilkara amazonica (Alencar 1990). De acordo com Alencar (1994), a disponibilidade de água parece ser uma necessidade importante para a frutificação das espécies da família Sapotaceae que apresentam frutos carnosos. Este padrão não foi confirmado para as espécies aqui estudadas que, apesar de apresentarem frutos carnosos, coloridos e liberados nos meses de fevereiro e março (final da estação chuvosa), mostraram uma correlação muito fraca entre frutificação e precipitação.

A curva de crescimento duplo-sigmoidal observada para os frutos das três espécies estudadas é semelhante à curva identificada para Argania spinosa (Sapotaceae), com alternância entre duas fases de crescimento lento e duas fases de crescimento rápido (Nerd et al. 1998). De acordo com Stephenson (1981), o crescimento dos frutos na maioria das espécies é sigmoidal, sucedendo-se fases de aumento do número de células, crescimento rápido das células associado à acumulação de recursos e crescimento lento associado a mudanças relacionadas com a maturação. A curva de crescimento duplosigmoidal foi registrada também para Prunus spp., Ficus carica L., Ribes nigrum L., Rubus spp., Vaccinium spp. e Vitis spp. (Coombe 1960 apud Stephenson 1981). Nesse caso divisões celulares geralmente ocorrem durante a primeira fase de crescimento lento e continuam ao longo da primeira fase de crescimento rápido. Embora as espécies estudadas apresentem a mesma curva de crescimento dos frutos, ocorrem diferenças no tamanho final dos mesmos, no tempo gasto em cada fase e na extensão do período necessário para a maturação. Nerd et al. (1998) também observaram que um número significativo de frutos de Argania spinosa abortava na fase inicial de crescimento.

O presente estudo conclui que três das cinco espécies de Sapotaceae ocorrentes na restinga de Maricá apresentam 
padrões de floração e de frutificação muito semelhantes, com eventos de floração incluídos nos meses com menores temperaturas e índices pluviométricos e eventos de frutificação nos meses mais quentes e úmidos do ano. Esse padrão reforça a importância da família, em áreas de restinga, como importantes elementos mantenedores de recursos florais para insetos polinizadores, na época mais fria e seca do ano, e de frutos carnosos disponíveis para animais dispersores de sementes, no final da estação mais quente e úmida do ano.

Agradecimentos - Ao CNPq e a Faperj pela bolsa concedida à primeira autora.

\section{Referências Bibliográficas}

ANDRADE, J.C. \& ANDRADE, A.G. 1983. Pouteria psammophila var. xestophylla (Miq. et. Eichl.) Baehni - Sapotaceae - no litoral do Rio de Janeiro: um alerta de extinção. Atas de Sociedade Botânica do Brasil, RJ $1: 1-7$.

ALENCAR, J.C. 1990. Interpretação fenológica de espécies lenhosas de Campina na Reserva Biológica de Campina do INPA ao Norte de Manaus. Acta Amazonica 20:145183.

ALENCAR, J.C. 1994. Fenologia de cinco espécies arbóreas tropicais de Sapotaceae correlacionadas a variáveis climáticas na Reserva Ducke, Manaus, AM. Acta Amazonica 24:161-182.

ALMEIDA, E.M. \& ALVES, M.A.S. 2000. Fenologia de Psychotria nuda e P. brasiliensis (Rubiaceae) em uma área de floresta atlântica no Sudeste do Brasil. Acta Botanica Brasilica 14:335-346.

BARROS, M.A.G. 1992. Fenologia da floração, estratégias reprodutivas e polinização de espécies simpátricas do gênero Byrsonima Rich. (Malpighiaceae). Revista Brasileira de Biologia 52:343-353.

BAWA, K.S. 1983. Patterns of flowering in tropical plants. In Handbook of experimental pollination biology (C.E. Jones \& R.J. Little, eds.). Scientific and Academic editions, New York.

BIANCHI, E., PIMENTA, J.A. \& SANTOS, F.A.M. 2006. Fenologia de Chrysophyllum gonocarpum (Mart. \& Eichler) Engl. (Sapotaceae) em floresta semidecídua do Sul do Brasil. Revista Brasileira de Botânica 29:595602.

CARVALHO, C.A.L. \& MARCHINI, L.C. 1999. Plantas visitadas por Apis mellifera $\mathrm{L}$. no vale do rio Paraguaçu Município de Castro Alves, Bahia. Revista Brasileira de Botânica 22:333-338.

CORREIA, M.C.R., PINHEIRO, M.C.B. \& LIMA, H.A. 2005. Biologia floral e polinização de Arrabidaea conjugata (Vell.) Mart. (Bignoniaceae). Acta Botanica Brasilica 19:501-510.
CORREIA, M.C.R., PINHEIRO, M.C.B. \& LIMA, H.A. CORREIA. 2006. Biologia floral e polinização de Anempaegma chamberlaynii Bur. \& K.Shum. (Bignoniaceae). Lundiana 7:39-46.

CROAT, T.B. 1969. Seasonal flowering behavior in Central Panamá. Annals of the Missouri Botanical Garden 56:295-307.

DAU, L. 1960. Microclimas das restingas do sudeste do Brasil. I - Restinga interna de Cabo Frio. Separata dos Arquivos do Museu Nacional 50:70-134.

FALCÃO, M.A. \& CLEMENT, C.R. 1999. Fenologia e produtividade do abiu (Pouteria caimito) na Amazônia Central. Acta Amazonica 29:3-11.

FERREIRA, R.C.N. 2000. Espécies arbóreas ameaçadas de extinção das restingas do norte fluminense. Considerações sobre sua conservação mediante ao emprego paisagístico. Dissertação de mestrado, Universidade Federal do Rio de Janeiro, Rio de Janeiro.

FOURNIER, G.W. \& CHARPANTIER, C. 1975. El tamaño de la muestra e la frecuencia de las observaciones en el studio de las características fenológicas de los árboles tropicales. Turrialba 25:45-48.

FRANKIE, G.W., BAKER, H.G. \& OPLER, P.A. 1974. Comparative phenological studies of trees in tropical wet and dry forests in the lowlands of Costa Rica. Journal of Ecology 62:881-913.

GARCIA, E.G. \& DI STEFANO, J.F. 2003. Fenologia del árbol Sideroxylon capiri (Sapotaceae) en el Bosque Seco Tropical de Costa Rica. Revista de Biologia Tropical 53:5-14

GENTRY, A.H. 1974. Flowering phenology and diversity in tropical Bignoniceae. Biotropica 6:64-68.

HENRIQUES, R.P.B., ARAUJO, D.S.D. \& HAY, J.D. 1986. Descrição e classificação dos tipos de vegetação da restinga de Carapebus, RJ. Revista Brasileira de Botânica 9:173-189.

JUSTICIANO, M.J. \& FREDERICKSEN, T.S. 2000. Phenology of tree species in Bolivian dry forests. Biotropica 32:276-281.

LARCHER, W. 2000. Ecofisiologia vegetal. Editora RiMa, São Carlos.

LIETH, H. 1974. Introduction to phenology and the modeling of seasonality. In Phenology and seasonality modeling (H. Lieth, ed.). Spring Verlag, Berlin, p.3-19.

LOURO, R.P. \& SANTIAGO, L.J.M. 1984. A região de Barra de Maricá, RJ e a importância de sua preservação. Atas da Sociedade Botânica do Brasil, RJ 2:105-118.

MAIA, V.C. 2001. The gall midges (Diptera, Cecidomyiidae) from three restingas of Rio de Janeiro State, Brazil. Revista Brasileira de Zoologia 18:583-629.

MANTOVANI, A. \& IGLESIAS, R.R. 2001. Bromélias terrestres na restinga de Barra de Maricá, Rio de Janeiro: Influência sobre o microclima, o solo e a estocagem de nutrientes em ambientes de borda de moitas. Leandra 16:17-37. 
MARQUES, M.C.M. \& OLIVEIRA, P.E.A.M. 2004. Fenologia de espécies do dossel e do sub-bosque de duas Florestas de Restinga na Ilha do Mel, sul do Brasil. Revista Brasileira de Botânica 27:713-123.

MELLO-FILHO, L.E., SOMNER, G.V. \& PEIXOTO, A.L. 1992. Centuria plantarum brasiliensium extintions minitata. Sociedade Botânica do Brasil/IBAMA, Brasil.

NERD, A., IRIDJIMOVICH, V. \& MIZRAHI, Y. 1998. Phenology, breeding system and fruit development of Argan (Argan spinosa, Sapotaceae) cultivated in Israel. Economic Botanic 52:161-167.

NEWSTROM, L.E., FRANKIE, G.W. \& BAKER, H.G. 1994. A new classification for plant phenology based on flowering patterns in lowland tropical rain forest trees at La Selva, Costa Rica. Biotropica 26:141-159.

NOUAIM, R., CHAUSSOD, R. EL-ABOUDI, A. \& MIZRAHI, Y. 1991. L'arganier: essai de synthèse des connaissances sur cet arbre. In Physiologie des arbres et arbustes en Zones Arides et Semi-Arides (Groupe d'Étude de l'Arbre, eds.). John Libbey Eurotex, Paris. p.373-388.
ORTEGA, L.C.S. de. 1986. Etudes floristiques de divers stades secondaires des formations forestieres du Hault Parana (Paraguai oriental). Floraison, fructification et dispersion des especes forestieres. Candollea 4:121144.

SILVA, J.C. \& OLIVEIRA, A.S. 1989. A vegetação da restinga no Município de Maricá, RJ. Acta Botanica Brasilica (suplemento) 3:253-272.

STATSOFT - STATISTICA. 1991. Tulsa: Statsoft, software, version 6.0 .

STEEGE, H. \& PERSAUD, C.A. 1991. The phenology of Guyanese timber species: a compilation of a century of observations. Vegetatio 95:177-198.

STEPHENSON, A.G. 1981. Flower and fruit abortion: proximate causes and ultimate functions. Annual Review of Ecology and Systematics 12:253-279.

TALORA, D.C. \& MORELLATO, L.P.C. 2000. Fenologia de espécies arbóreas em floresta de planície litorânea do sudeste do Brasil. Revista Brasileira de Botânica 23:13-26. 